\title{
MODE-CONVERTING CORRUGATIONS FOR CAVITIES OF SECOND-HARMONIC GYROTRONS WITH IMPROVED PERFORMANCE
}

\author{
DTetiana I. Tkachovaa,*, (DVitalii I. Shcherbinin ${ }^{a}$, (DViktor I. Tkachenko ${ }^{a, b}$ \\ ${ }^{a}$ National Science Center "Kharkiv Institute of Physics and Technology", 61108 Kharkiv, Ukraine \\ ${ }^{b}$ V.N. Karazin Kharkiv National University, 61022 Kharkiv, Ukraine \\ *Corresponding Author: t.i.tkachova@gmail.com \\ Received March 23, 2021; revised April 7, 2021; accepted April 10, 2021
}

\begin{abstract}
A new method of improving mode selection in cavities of sub-terahertz second-harmonic gyrotrons is investigated. As an example, a second-harmonic gyrotron with frequency of $0.3 \mathrm{THz}$ is considered. The gyrotron is designed for collective Thomson scattering (CTS) diagnostics of fusion plasmas and has a limited output power due to competition between the operating TE $\mathrm{E}_{13,2}$ mode and firstharmonic modes. For suppression of the first-harmonic competing modes periodic longitudinal corrugations are used in the gyrotron cavity. Such corrugations can induce coupling of the normal cavity modes known as azimuthal Bloch harmonics. The corrugation depth is set close to the half- and quarter-wavelength of the operating second-harmonic mode and competing first-harmonic modes, respectively. Under this condition, longitudinal corrugations of the cavity generally have only a slight effect on the operating mode, but can initiate strong conversion of the competing modes to high-order Bloch harmonics. The full-wave method of coupled azimuthal harmonics is applied to investigate the influence of dimensions of the corrugated gyrotron cavity on eigenvalues, ohmic losses and beam-wave coupling coefficients for the operating TE 13,2 mode and the most dangerous competing modes. Using the selfconsistent theory of beam interaction with the operating and competing modes, the most optimal parameters are found for a gyrotron cavity with mode-converting corrugations, which ensure the widest range of a single mode operation for the $0.3-\mathrm{THz}$ secondharmonic gyrotron. It is shown that, in this range, the gyrotron output power can be increased from $100 \mathrm{~kW}$ to $180 \mathrm{~kW}$, as required by CTS plasma diagnostics. It is found that output mode purity of the 0.3 -THz second-harmonic gyrotron falls off due to modeconverting corrugations, which induce undesirable coupling of the operating $\mathrm{TE}_{13,2}$ mode with neighboring Bloch harmonics in the output section of the gyrotron cavity.
\end{abstract}

KEYWORDS: gyrotron, cyclotron harmonic, cavity, mode-converting corrugations, starting current, output power

Gyrotron is the most powerful source of sub-terahertz waves for widespread applications, including advanced spectroscopic methods, material processing, sensing and imaging techniques, biomedical research, plasma diagnostics, etc. [1-4]. It is a vacuum electron device, which is capable of producing more than $100 \mathrm{~kW}$ of output power in the frequency range between 0.1 and $0.4 \mathrm{THz}$. This capability of a gyrotron makes it the only suitable radiation source for plasma diagnostics based on collective Thomson scattering (CTS) [5-7]. However, in a gyrotron, high operating frequency places a stringent requirement on applied magnetic field, which is intended to guide a helical electron beam.

This requirement is much relaxed in gyrotrons operated at the second (or higher) harmonics of the cyclotron frequency. That is why second-harmonic gyrotrons with medium-field magnets are recognized as advantageous radiation sources in the sub-terahertz-to-terahertz frequency range. However, in these gyrotrons, an additional constraint on output power emerges $[5,6]$. It is imposed by competition from the first-harmonic modes, which inherently possess low oscillation thresholds (starting currents).

To discriminate against the first-harmonic competing modes advanced gyrotron cavities with improved mode selection are required. Among them are coaxial cavities [8-12]. In a coaxial cavity, the modes are discriminated by a coaxial insert. The insert dimensions are usually selected to be small enough to have only a slight effect on the operating mode. Therefore, the operation of a coaxial-cavity gyrotron benefits from little sensitivity to the fabrication imperfections and misalignment of the coaxial loading. Unlike the operating mode, competing modes, which have smaller caustic radii, are suppressed by losses induced by the coaxial insert. The first-harmonic whispering-gallery (WG) modes are usually the remaining competitors, which can hinder high-performance operation of second-harmonic gyrotrons [11, 12].

Mode-converting wall corrugations can be applied to further improve the selectivity properties of advanced cavities for second-harmonic gyrotrons [13, 14]. Contrary to impedance corrugations [15-19], such corrugations induce coupling between normal modes (azimuthal Bloch harmonics) of the cavity and thereby affect frequencies of cavity modes, their ohmic losses and coupling with an electron beam [20-22]. According to [13, 14], in a cavity of a secondharmonic gyrotron, the depth of mode-converting corrugations should be selected close to half wavelength of the operating mode. In this case, the operating mode is generally weakly affected by corrugations of the cavity wall, while characteristics of the first-harmonic competing modes undergo a material change. As a result, the corrugation width and number can be optimized in such a way as to provide the most efficient suppression of the first-harmonic competitors in a corrugated cavity of a second-harmonic gyrotron. Thus, in a second-harmonic gyrotron, the use of a cavity with optimized corrugations is expected to have a beneficial effect on stability and efficiency of single-mode operation. The aim of this paper is to provide the design of the gyrotron cavity with mode-converting corrugations, which aid in suppressing the first-harmonic WG modes and improving the performance of a second-harmonic gyrotron. As an example, we consider the 0.3-THz second-harmonic gyrotron designed for CTS diagnostics of fusion plasmas [11]. In 
coaxial cavity of this gyrotron, the operating $\mathrm{TE}_{13,2}$ mode and first-harmonic WG modes are the only modes, which are unaffected by the coaxial insert and are identical to modes supported by a hollow cylindrical cavity.

\section{BASIC EQUATIONS}

In a gyrotron, an electromagnetic radiation is produced by the interaction between a helical beam of electrons gyrating in applied magnetic field $\mathbf{B}_{0}=B_{0} \mathbf{e}_{z}$ and TE mode $\left(E_{z}=0\right)$ excited at the $s$-th harmonic of cyclotron frequency $\omega_{c 0}$ in a metal cylindrical cavity. In the general form, this interaction is described by the following system of equations:

$$
\left\{\begin{array}{l}
\left(\Delta_{\perp}+\frac{\partial^{2}}{\partial z^{2}}+k^{2}\right) \operatorname{Re} \mathbf{E}_{\perp}=-i \frac{4 \pi k}{c} \mathbf{j}_{\perp} \\
\frac{d \mathbf{p}}{d t}=-e\left(\mathbf{E}+\frac{1}{c}\left[\mathbf{v} \times\left(\mathbf{B}+\mathbf{B}_{\mathbf{0}}\right)\right]\right)
\end{array},\right.
$$

where $\mathbf{p}=m_{e} \mathbf{v} \gamma, \mathbf{v}, \gamma=\left(1-v^{2} / c^{2}\right)^{-1 / 2}, e$ and $m_{e}$ are the momentum, velocity, relativistic factor, charge and rest mass of beam electrons, respectively, $\mathbf{j}_{\perp}$ is the transverse component of beam current density, $c$ is the speed of light in vacuum, $\{\mathbf{E}(\mathbf{r}, t), \mathbf{B}(\mathbf{r}, t)\}=\{\mathbf{E}(\mathbf{r}), \mathbf{B}(\mathbf{r})\} \exp (-i \omega t)$ are the electric and magnetic fields of TE mode, $\omega$ is the angular frequency, $k=\omega / c$.

In cylindrical coordinates $\{r, \varphi, z\}$, the field components of TE mode can be written as

$$
\begin{gathered}
E_{r}=\frac{i k}{r} V(z) \frac{\partial \Psi}{\partial \varphi}, E_{\varphi}=-i k V(z) \frac{\partial \Psi}{\partial r}, \\
B_{z}=k_{\perp}^{2} V(z) \Psi, B_{r}=V^{\prime}(z) \frac{\partial \Psi}{\partial r}, B_{\varphi}=\frac{1}{r} V^{\prime}(z) \frac{\partial \Psi}{\partial \varphi},
\end{gathered}
$$

where $V(z)$ and $k_{\perp}$ are the mode amplitude and transverse wavenumber, respectively, $\Psi=\Psi(r, \varphi)$ is the membrane function, which satisfies the Helmholtz equation $\Delta_{\perp} \Psi=-k_{\perp}^{2} \Psi$ and describes the transverse field structure in the gyrotron cavity.

We consider an open-ended cylindrical cavity, which incorporates longitudinal wedge-shaped corrugations (Fig. 1).

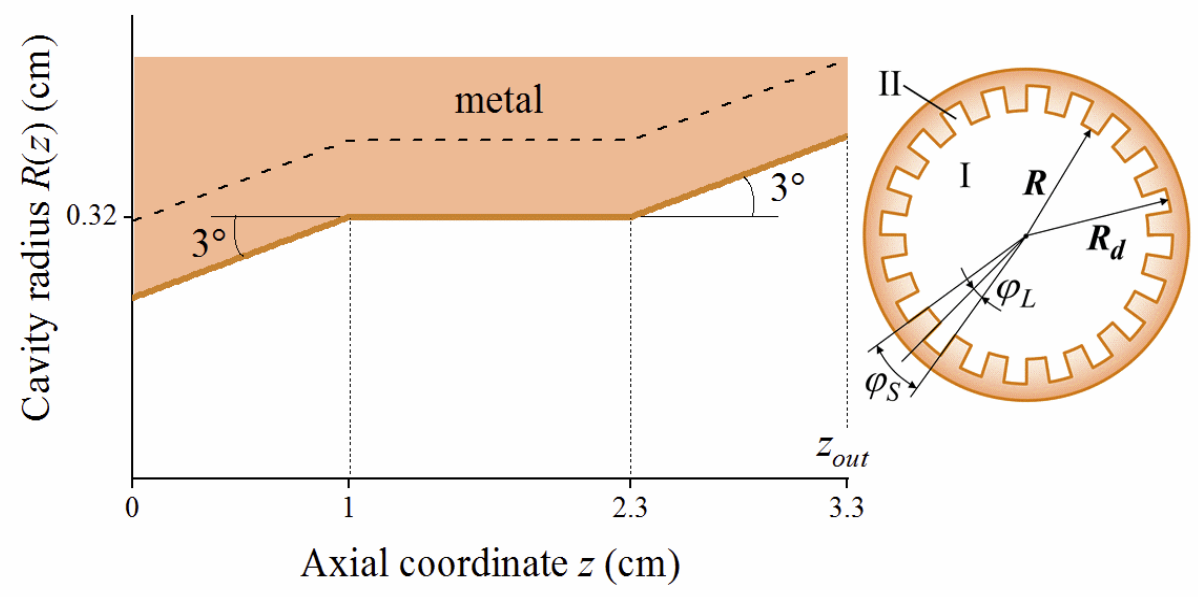

Figure 1. Longitudinal and transverse cross-sections of the corrugated cylindrical cavity

In such gyrotron cavity, the membrane function has the form $[13,20,22]$

$$
\Psi=\left\{\begin{array}{l}
\sum_{n=-\infty}^{\infty} A_{n} f_{n}(r) \exp \left(i k_{n} \varphi\right), 0<r<R \\
\sum_{l=0}^{\infty} X_{l} g_{l}(r) \cos \left(\xi_{l}\left(\varphi+\frac{\varphi_{L}}{2}\right)\right), \quad R<r<R_{d}
\end{array}\right.
$$


where $f_{n}(r)=J_{k_{n}}\left(k_{\perp} r\right) / J_{k_{n}}^{\prime}\left(k_{\perp} R\right), k_{n}=m+n N$ is the azimuthal index of the $n$-th Bloch harmonic, $N$ is the number of periodic corrugations, $R$ is the cavity radius, $g_{l}(r)=\frac{J_{\xi_{l}}\left(k_{\perp} r\right) N_{\xi_{l}}^{\prime}\left(k_{\perp} R_{d}\right)-J_{\xi_{l}}^{\prime}\left(k_{\perp} R_{d}\right) N_{\xi_{l}}\left(k_{\perp} r\right)}{J_{\xi_{l}}^{\prime}\left(k_{\perp} R\right) N_{\xi_{l}}^{\prime}\left(k_{\perp} R_{d}\right)-J_{\xi_{l}}^{\prime}\left(k_{\perp} R_{d}\right) N_{\xi_{l}}^{\prime}\left(k_{\perp} R\right)}, \xi_{l}=\frac{\pi l}{\varphi_{L}}, J_{m}(\cdot)$ and $N_{m}(\cdot)$ are the $m$-th order Bessel and Neumann functions, respectively, $R_{d}=R+d, d$ and $w=\varphi_{L} R$ are the corrugation depth and width, respectively.

The transverse wavenumber $k_{\perp}=R^{-1} \chi\left(1-i /\left(2 Q_{o h m}\right)\right)$ and membrane function $\Psi$ are derived from the boundary and continuity conditions for the field (2). Here $Q_{\text {ohm }}$ is the Q-value associated with ohmic losses of the TE mode in a metal gyrotron cavity with finite electric conductivity $\sigma$. For the $\mathrm{TE}_{m, p}$ mode of a smooth-walled cylindrical cavity ( $d=0$ or $w=0$ ), one obtains $\chi=\mu_{m, p}^{\prime}, Q_{o h m}=Q_{o h m}^{(0)} \approx R / \delta_{s}\left(1-m^{2} / \mu_{m, p}^{\prime 2}\right)$ and $\Psi=A_{0} f_{0}(r) \exp (\operatorname{im} \varphi)$, where $\delta_{s}$ is the skin-depth and $\mu_{m, p}^{\prime}$ is the $p$-th root of the function $J_{m}^{\prime}(\cdot)$.

The amplitude $V(z)$ of the TE mode and electron beam dynamic can be found from (1), initial conditions for beam electrons and outgoing-wave boundary conditions at both ends of the cavity (for more detail, see [14]). Hence one can determine the transverse electronic efficiency $\eta_{\perp}=1-\left\langle\left|\mathbf{p}_{\perp e}\right|^{2} /\left|\mathbf{p}_{\perp 0}\right|^{2}\right\rangle$ as a function of beam parameters and cavity dimensions, where $\langle\cdot\rangle$ denotes averaging over the beam electrons having the initial $\mathbf{p}_{\perp 0}$ and final $\mathbf{p}_{\perp e}$ transverse momenta. The efficiency $\eta_{\perp}$ is greater than zero, if the beam current $I_{b}=\int j_{z} d S_{\perp}$ exceeds the oscillation threshold $I_{s t}$ known as a starting current.

One of the main factors affecting the interaction efficiency is the beam coupling with $s$-th harmonic TE mode. In a cavity with longitudinal wall corrugations, each TE mode has the form of multiple Bloch harmonics (see (3)), which have their own beam-wave coupling coefficients. For the $n$-th Bloch harmonic with amplitude $A_{n}$, such coefficient reads as [14]:

$$
C_{n, s}^{2}=A_{n}^{2} \frac{J_{k_{n}-s}^{2}\left(k_{\perp} r_{c}\right)}{N_{m n}},
$$

where $r_{c}$ is the beam radius,

$$
\begin{aligned}
& N_{m n}=\sum_{n=-\infty}^{\infty}\left|A_{n}\right|^{2}\left[\chi^{2}+2 \chi f_{n}(\chi)+\left(\chi^{2}-k_{n}^{2}\right) f_{n}^{2}(\chi)\right]+\frac{\varphi_{L}}{\varphi_{S}} \chi^{2}\left|X_{0}\right|^{2}\left[\left(\frac{R_{d}^{2}}{R^{2}}-\frac{1}{\chi^{2}}\right) g_{1}^{2}\left(\chi \frac{R_{d}}{R}\right)-\left(1-\frac{1}{\chi^{2}}\right) g_{1}^{2}(\chi)-1\right]+ \\
& +\frac{\varphi_{L}}{\varphi_{S}} \frac{\chi^{2}}{2} \sum_{l=1}^{\infty}\left|X_{l}\right|^{2}\left[\left(\frac{R_{d}^{2}}{R^{2}}-\frac{\xi_{l}^{2}}{\chi^{2}}\right) g_{l}^{2}\left(\chi \frac{R_{d}}{R}\right)-\frac{2}{\chi} g_{l}(\chi)-\left(1-\frac{\xi_{l}^{2}}{\chi^{2}}\right) g_{l}^{2}(\chi)-1\right] .
\end{aligned}
$$

Among Bloch harmonics, there is always a dominant harmonic with maximal beam-wave coupling strength $C_{s}=\max \left\{C_{n, s}^{2}\right\}$. Usually such harmonic has the main effect on efficiency of beam interaction with $s$-th harmonic TE mode supported by a corrugated gyrotron cavity.

From the knowledge of the interaction efficiency, one can determine the total power of TE mode interacting with the helical electron beam

$$
P_{t o t}=\eta_{e l} I_{b} V_{b}
$$

where $\eta_{e l}=\eta_{\perp} \alpha^{2} /\left(1+\alpha^{2}\right)$ is the total electronic efficiency, $V_{b}$ is the beam voltage, $\alpha=v_{\perp 0} / v_{z 0}$ is the pitch factor, $v_{\perp 0}$ and $v_{z 0}$ are the initial transverse and longitudinal electron velocities, respectively.

Inside the interaction region, the total wave power must be balanced in accordance with the following conservation law:

$$
P_{\text {tot }}=P_{\text {out }}+P_{\text {ohm }}
$$

where $P_{\text {out }}$ is the output power leaked out from the output end $\left(z=z_{\text {out }}\right)$ of the gyrotron cavity (Fig. 1) and $P_{\text {ohm }}$ is the ohmic power dissipated in metal cavity walls. 
For the cylindrical cavity with longitudinal wall corrugations, the power balance condition (6) can be reduced to the following dimensionless form:

$$
I_{0} \eta_{\perp}=2 \operatorname{Re} \delta\left|f\left(\xi_{\text {out }}\right)\right|^{2}+\frac{16 \beta_{z 0}^{2}}{\beta_{\perp 0}^{4}} \operatorname{Re}\left(Z_{s} G_{m n}\right),
$$

where $I_{0}=64 \frac{I_{b}}{I_{A}} \frac{\beta_{z 0}}{\gamma_{0}}\left[\frac{\beta_{\perp 0}^{s-4}}{(s-1) ! 2^{s}}\left(\frac{\omega}{\omega_{c 0}}\right)^{s-1}\right]^{2}, I_{A}=m_{e} c^{3} / e \approx 17$ is the Alfven current, $\gamma_{0}=1+\frac{e V_{b}}{m_{e} c^{2}}$ is the initial relativistic factor, $\beta_{\perp 0}=\frac{\nu_{\perp 0}}{c}, \quad \beta_{z 0}=\frac{v_{z 0}}{c}, \omega_{c 0}=\frac{e B_{0}}{m_{e} c \gamma_{0}}, f(\xi)=-V(z) \frac{2 \omega}{I_{A} \gamma_{0}} \frac{\beta_{\perp 0}^{s-4}}{(s-1) ! 2^{s}}\left(\frac{\omega}{\omega_{c 0}}\right)^{s-1} \sqrt{N_{m n}} \exp \left(-i \frac{s}{2} \pi\right)$, $\xi=z \frac{k \beta_{\perp 0}^{2}}{2 \beta_{z 0}}, \quad \delta=\frac{2 \beta_{z 0}}{k \beta_{\perp 0}^{2}} \sqrt{k^{2}-k_{\perp}^{2}}, \quad Z_{s}=(1-i) k \delta_{s}$ is the normalized impedance of the conducting surface, $G_{m n}=\int_{0}^{\xi_{o u t}} d \xi \frac{k_{\perp}^{3} \chi}{k^{3} N_{m n}}|f(\xi)|^{2}\left\{\left(1-\frac{\varphi_{L}}{\varphi_{S}}\right) \sum_{n=-\infty}^{\infty}\left|A_{n}\right|^{2} f_{n}^{2}(\chi)+\frac{\varphi_{L} R_{d}}{2 \varphi_{S} R} \sum_{l=0}^{\infty}\left|X_{l}\right|^{2}\left(1+\delta_{l 0}\right) g_{l}^{2}\left(\chi \frac{R_{d}}{R}\right)+\frac{N}{\pi R} \sum_{l=0}^{\infty}\left|X_{l}\right|^{2} \int_{R}^{R_{d}} g_{l}^{2}\left(\chi \frac{r}{R}\right) d r\right\}$, $\delta_{i j}$ is the Kronecker delta.

The relation (7) provides useful check on numerical solutions of the self-consistent system of equations (1). As the corrugation depth or width approaches zero, it reduces to the well-known condition of power balance in a smoothwalled cylindrical gyrotron cavity [23].

\section{EIGENVALUES AND OHMIC LOSSES OF THE CAVITY WITH LONGITUDINAL WALL} CORRUGATIONS

In a gyrotron cavity, the effect of longitudinal wall corrugations is mainly determined by the ratio of corrugation depth $d$ to mode cutoff wavelength $\lambda=2 \pi R / \chi$ and therefore is different for the first-harmonic $(s=1)$ and secondharmonic $(s=2)$ modes [13,21]. It alters the mode eigenvalue $\chi$, ohmic quality factor $Q_{\text {ohm }}$ and beam-wave coupling coefficient $C_{s}$. One can take advantage from this fact with the goal to discriminate against the first-harmonic competing modes of the second-harmonic gyrotron.

As an example, the 0.3-THz second-harmonic gyrotron operated in the $\mathrm{TE}_{13,2}$ mode [11] is considered. The beam parameters are as follows: $I_{b}=10 \mathrm{~A}, V_{b}=60 \mathrm{kV}, \alpha=1.2$ and $r_{c}=0.2 \mathrm{~cm}$. The gyrotron is originally equipped with a smooth-walled coaxial cavity of the radius $R=0.32 \mathrm{~cm}$. A coaxial insert of the cavity is used to suppress all first- and second-harmonic competing $\mathrm{TE}_{m, p}$ modes with relatively small caustic radii $R_{m, p}=R|m| / \mu_{m, p}^{\prime}$. However, it has no effect on the first-harmonic WG modes with $|m| / \mu_{m, p}^{\prime}>0.7$. These modes are close to those of a hollow cylindrical cavity and may constitute a threat to high-performance operation of the $0.3-\mathrm{THz}$ second-harmonic gyrotron.

We consider longitudinal corrugations of the cavity wall as a possible means for discrimination against WG competing modes of the $0.3-\mathrm{THz}$ second-harmonic gyrotron. The coaxial insert of the cavity is ignored. The corrugations are assumed to have the depth $d=0.05 \mathrm{~cm}$ and width $w=0.02 \mathrm{~cm}$. The corrugation depth of $0.05 \mathrm{~cm}$ is adopted to fulfill the condition $d \approx \lambda / 2$ for the operating $\mathrm{TE}_{13,2}$ mode. Under this condition, the effect of wall corrugations on the operating mode is generally weak $[13,14]$.

Fig. 2a shows the cutoff frequencies $f_{c}=c \chi /(2 \pi R)$ of the gyrotron cavity versus the number $N$ of corrugations for $m=13$. One can see that within the frequency spectrum, there is the mode, which has the eigenvalue close to $\mu_{13,2}^{\prime}$ for a wide range of $N$. This mode is the operating mode, which has the form of nearly pure fundamental $(n=0)$ Bloch harmonic with $k_{0}=m=13$ and resembles the $\mathrm{TE}_{13,2}$ mode of the conventional smooth-walled cavity. Unfortunately, in close proximity to the operating mode, there is the mode $\left(f_{c} \approx 297.34 \mathrm{GHz}\right)$ with dominant high-order $(n \neq 0)$ Bloch component. It corresponds to the $\mathrm{TE}_{7,4}$ mode of a smooth-walled cavity. This mode (high-order Bloch harmonic) can be coupled with the $\mathrm{TE}_{13,2}$ mode (fundamental Bloch harmonic) for $N=2,3,4,5,6,10,20$. Even though such a mode coupling is generally weak for $d \approx \lambda / 2$, it may emerge in a corrugated gyrotron cavity with increase in mismatch between $d=0.05 \mathrm{~cm}$ and $\lambda / 2$. Because of fairly small caustic radius of the $\mathrm{TE}_{7,4}$ mode, this coupling must be avoided. Otherwise, one might expect suppression of the operating mode by a coaxial insert introduced in the original cavity of the $0.3-\mathrm{THz}$ second-harmonic gyrotron.

For the operating and neighboring modes, the maximal beam-wave coupling coefficients $C_{s}$ are shown in Fig. $2 \mathrm{~b}$. One can see that the operating mode exhibits the coefficient $C_{s}$, which is close to the coefficient $C_{s}^{(0)}$ of beam coupling 
with $\mathrm{TE}_{13,2}$ mode of the original smooth-walled cavity. The exceptions are $N=13$ and $N=20$. In this case, the operating $\mathrm{TE}_{13,2}$ mode suffers from conversion to high-order Bloch harmonics, which correspond to $\mathrm{TE}_{-13,2}$ and $\mathrm{TE}_{-7,4}$ modes and are characterized by weak coupling with electron beam. Clearly such situation is unfavorable for the operating mode.
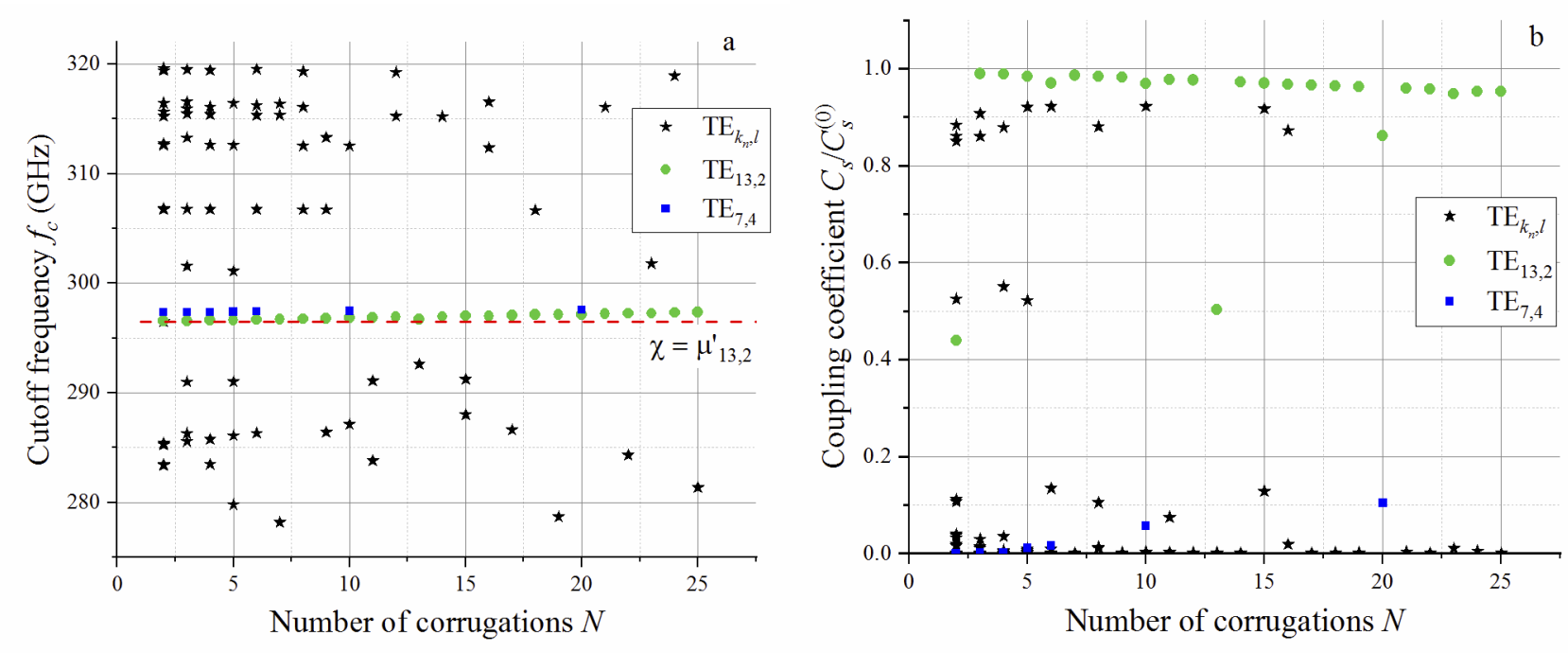

Figure 2. (a) Cutoff frequencies and (b) beam-wave coupling coefficients $C_{s} / C_{s}^{(0)}$ of modes of the corrugated gyrotron cavity versus the number $N$ of corrugations for $m=13$, where $C_{s}^{(0)}$ is the beam-wave coupling coefficient of the TE 13,2 mode of a smoothwalled cylindrical cavity

Fig. 3 shows the ohmic Q-value $Q_{o h m}$ of the operating $\mathrm{TE}_{13,2}$ mode versus the number of corrugations. As the conducting surface of the corrugated cavity expands with $N$, the ohmic Q-value decreases. For $N=13$ and $N=20$ one can see a distinct drop in $Q_{o h m}$. As discussed above, conversion of the operating mode to high-order Bloch harmonics happens in this case. Thus, in the design of the corrugated cavity for the $0.3-\mathrm{THz}$ second-harmonic gyrotron, the number of corrugations must not be set to $2,3,4,5,6,10,13,20$ to avoid degradation of the gyrotron performance due to conversion of the operating mode to neighboring Bloch harmonics.

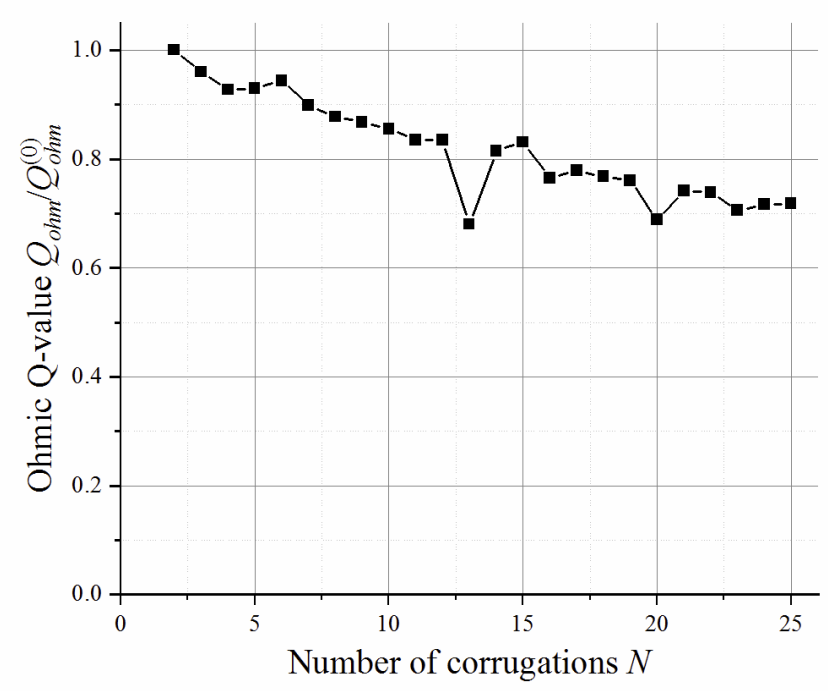

Figure 3. The ohmic Q-value of the operating mode supported by the corrugated gyrotron cavity versus the number $N$ of corrugations, where $Q_{o h m}^{(0)}$ is the ohmic Q-value of the TE 13,2 mode of a smooth-walled cylindrical cavity

The competing WG modes of the $0.3-\mathrm{THz}$ second-harmonic gyrotron are the first-harmonic modes with $m=7,8,9$. For these modes, the longitudinal corrugations, which have about a quarter-wavelength depth, initiate a strong coupling of multiple Bloch harmonics [13, 14]. Fig. 4a shows the cutoff frequencies of the corrugated gyrotron cavity versus $N$ for $m=7,8,9$. It is easy to see that decrease in $N$ magnifies the number of the first-harmonic 
competing modes in the vicinity of the operating mode. These competitors have the form of complex mixture of fundamental and high-order Bloch harmonics, which correspond to whispering-gallery and volume modes, respectively. Due to presence of the volume component, the competing modes might be suppressed, once a coaxial insert is introduced into the gyrotron cavity. However, it is not the goal of the present paper to investigate such possibility. For this reason, the design consideration is restricted to the cavity with relatively large number of corrugations, which provide fairly sparse spectrum of the first-harmonic competing modes of the $0.3-\mathrm{THz}$ second-harmonic gyrotron.
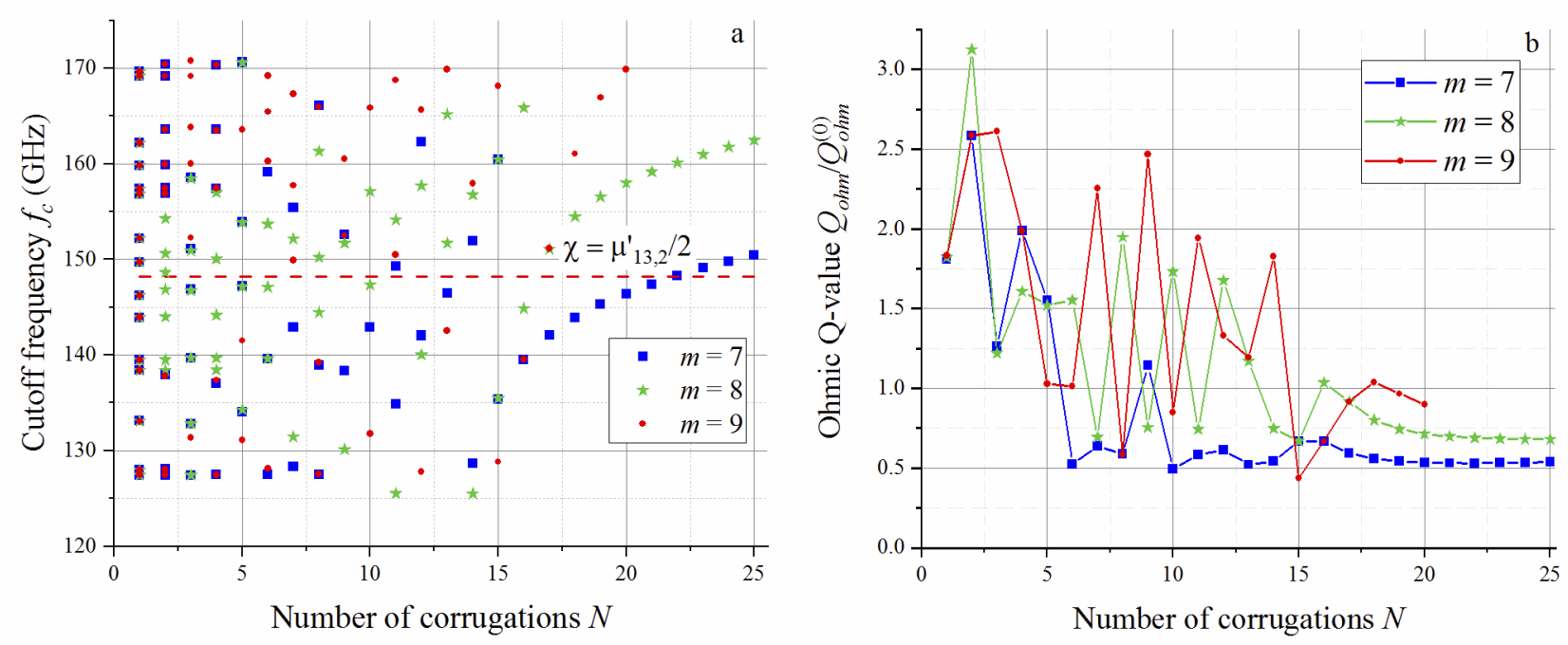

Figure 4. (a) The same as in Fig. 2a, but for $m=7,8,9$, and (b) the normalized ohmic Q-values of the most dangerous competing modes with $m=7,8,9$, where $Q_{o h m}^{(0)}$ is the ohmic Q-value of the TE8,1 mode of the smooth-walled cylindrical cavity

The effect of longitudinal corrugations of the cavity wall on the ohmic losses of the first-harmonic modes with $m=7,8,9$ is shown in Fig. 4b. In this figure, the ohmic Q-value is plotted as a function of $N$ for the most dangerous competing modes having the smallest frequency separation from the operating mode. One can see that the dependence of $Q_{o h m}$ on $N$ is non-monotonic. This is due to the fact that the composition of Bloch harmonics for these competitors changes abruptly with number of corrugations. Because of mode conversion the competing modes can have volumetric field pattern for some $N$. In this case, their ohmic Q-values exceed those of the first-harmonic WG modes of the smooth-walled gyrotron cavity.

One can conclude from the above discussion that the optimal number of longitudinal corrugations for the cavity of the $0.3-\mathrm{THz}$ second-harmonic gyrotron equals 15. First, for $N=15$ the operating $\mathrm{TE}_{13,2}$ mode is in the form of pure fundamental Bloch harmonic. Second, this mode features sufficiently high beam-wave coupling coefficient and ohmic Q-value. Third, first-harmonic competing modes are well separated from the operating mode and are somewhat suppressed by ohmic losses in the corrugated cavity. Finally, compared to the operating mode, the competing modes suffer from larger degradation of the beam-wave coupling strength in the gyrotron cavity equipped with 15 longitudinal corrugations. This can be seen from Table 1, where $C_{1}^{(0)}(s=1)$ and $C_{2}^{(0)}(s=2)$ are the coefficients of beam coupling with $\mathrm{TE}_{8,1}$ and $\mathrm{TE}_{13,2}$ modes of the smooth-walled gyrotron cavity, respectively. Thus, the optimized corrugations are expected to improve the selectivity properties of the cavity for the $0.3-\mathrm{THz}$ second-harmonic gyrotron.

Table 1. Beam-wave coupling coefficients for the operating $(s=2, m=13)$ and competing $(s=1, m=7,8)$ modes of the corrugated gyrotron cavity with $R=0.32 \mathrm{~cm}, d=0.05 \mathrm{~cm}, w=0.02 \mathrm{~cm}$, and $N=15$

\begin{tabular}{|c|c|c|c|}
\hline Mode & $\chi$ & $C_{s}$ & $C_{s} / C_{s}^{(0)}$ \\
\hline$m=13$ & 19.92 & 0.017 & 0.97 \\
\hline$m=7$ & 10.76 & 0.0078 & 0.68 \\
\hline$m=8$ & 10.76 & 0.0102 & 0.89 \\
\hline
\end{tabular}

\section{BEAM-WAVE INTERACTION IN A CORRUGATED CAVITY FOR THE 0.3-THZ SECOND-HARMONIC GYROTRON}

For the 0.3-THz second-harmonic gyrotron equipped with original smooth-walled cavity, the starting currents of the operating second-harmonic $\mathrm{TE}_{13,2}$ mode and competing first-harmonic $\mathrm{TE}_{8,1}$ mode are depicted in Fig. 5a by the dashed lines (see also [11]). One can see that the operating mode is the only oscillating mode in the wide range of magnetic fields from $5.78 \mathrm{~T}$ to $6.08 \mathrm{~T}$, provided that the beam current equals $10 \mathrm{~A}$. At the same time, at higher beam 
currents the competing $\mathrm{TE}_{8,1}$ mode presents a barrier to stable operation of the 0.3-THz second-harmonic gyrotron. Moreover, it seems likely that this mode can completely suppress the operating second-harmonic mode for $I_{b} \geq 15$.

Longitudinal corrugations with $d=0.05 \mathrm{~cm}, w=0.02 \mathrm{~cm}$ and $N=15$ are used in order to improve mode selection in the cavity of the $0.3-\mathrm{THz}$ second-harmonic gyrotron. The effect of wall corrugations on the starting current of the operating $\mathrm{TE}_{13,2}$ mode is shown in Fig. 5a. It is evident that this starting current is somewhat shifted due to corrugations, which have a slight effect on the eigenvalue $\chi$, ohmic Q-value $Q_{o h m}$ and beam-wave coupling coefficient $C_{s}$ of the operating mode.
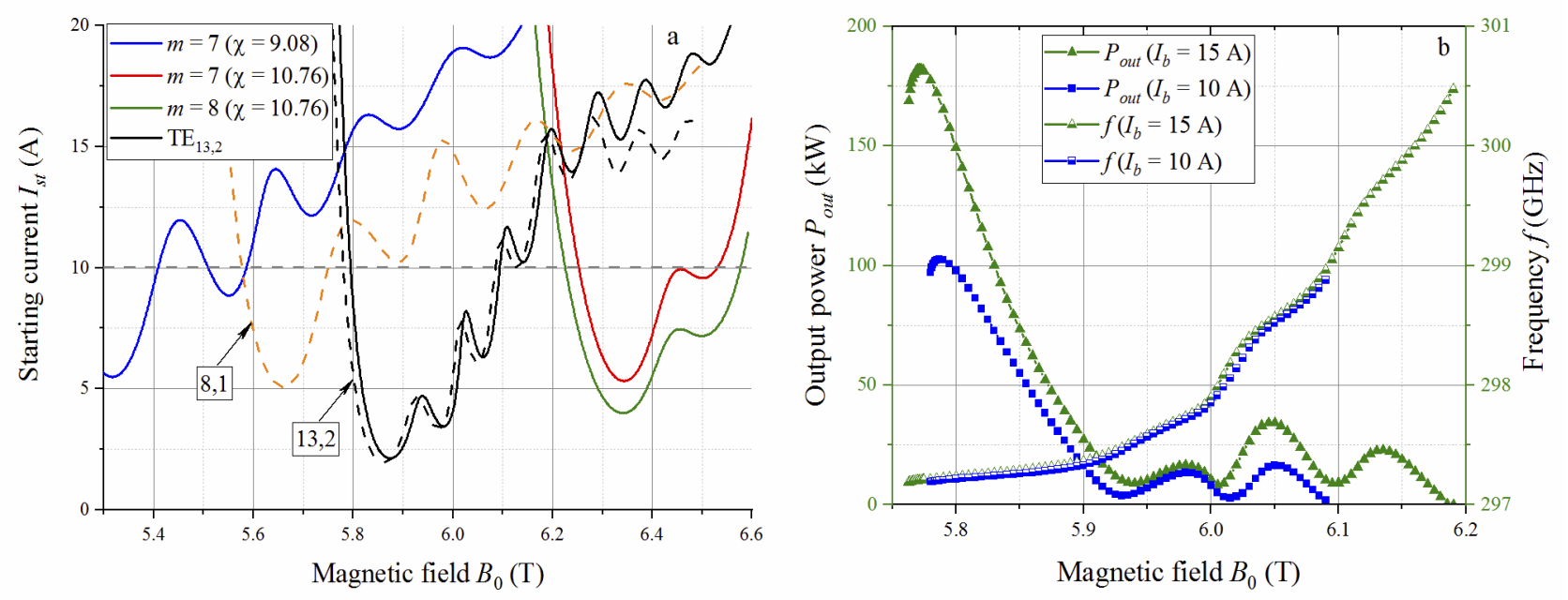

Figure 5. (a) Starting current as a function of the guided magnetic field for the operating $\mathrm{TE}_{13,2}$ mode and first-harmonic WG modes of the $0.3-\mathrm{THz}$ second-harmonic gyrotron equipped with optimized corrugated cavity and (b) the gyrotron output power versus $B_{0}$ for $I_{b}=10 \mathrm{~A}$ and $I_{b}=15 \mathrm{~A}$

In contrast to this, the first-harmonic competing modes of the $0.3-\mathrm{THz}$ second-harmonic gyrotron are radically altered by corrugations of the cavity wall. Fig. 5a shows the starting currents for the most dangerous modes, which lie close to the gyrotron operating region. Among them, there are no modes with azimuthal index $m=9$. The remaining competing modes have the form of coupled Bloch harmonics with $\left|k_{n}\right|=7$ and $\left|k_{n}\right|=8$. This is because 15 corrugations of the gyrotron cavity induce coupling between co-rotating fundamental harmonics with $m=+7$ and $m=+8$ and counter-rotating negative first harmonics with $k_{-1}=-8$ and $k_{-1}=-7$, respectively. Such two pairs of coupled Bloch harmonics form two cavity modes, which have identical eigenvalues and differ in beam-wave coupling strength. Examples are two modes having the eigenvalue $\chi=9.08$. Among them, the mode with $k_{0}=m=+7$ exhibits the strongest coupling with electron beam and therefore has a fairly small starting current (Fig. 5a). By contrast, the other mode with $k_{0}=m=+8$ is weakly coupled with beam and has the starting current larger than $22 \mathrm{~A}$, which is far apart from the oscillation region of the operating $\mathrm{TE}_{13,2}$ mode. As is seen from Fig. 5a, application of the cavity with optimized longitudinal corrugations extends a single-mode oscillation region of the $0.3-\mathrm{THz}$ second-harmonic gyrotron. As a consequence, the operating mode becomes free from any competing modes for the beam currents up to $15 \mathrm{~A}$. This situation is favorable for increasing the output power of the $0.3-\mathrm{THz}$ second-harmonic gyrotron.

Fig. $5 \mathrm{~b}$ shows the output power of the $0.3-\mathrm{THz}$ second-harmonic gyrotron versus magnetic field for $I_{b}=10 \mathrm{~A}$ and $I_{b}=15 \mathrm{~A}$. One can see that increase in beam current from $10 \mathrm{~A}$ to $15 \mathrm{~A}$ makes it possible to enhance the peak output power from $100 \mathrm{~kW}$ to $180 \mathrm{~kW}$ and widens the frequency tuning range of the operating $\mathrm{TE}_{13,2}$ mode. It should be stressed that the operating mode is the sole oscillating mode in this range. Thus, there are no obstacles for stable singlemode operation of the $0.3-\mathrm{THz}$ second-harmonic gyrotron with increased beam current and output power.

However, along with beneficial properties of the corrugated cavity for the $0.3-\mathrm{THz}$ second-harmonic gyrotron, there is a drawback. The operating mode undergoes conversion to high-order Bloch harmonics in the output up-tapered section of the cavity. The reason is that, in this section, increase in cavity radius enlarges the cutoff wavelength $\lambda$ of the operating mode and thus causes an increase between $\lambda / 2$ and corrugation depth $d=0.05 \mathrm{~cm}$. The operating $\mathrm{TE}_{13,2}$ mode converts to Bloch harmonics with $k_{-1}=-2$ and $k_{-2}=-17$ in the output cavity section. As a consequence, the purity of this mode falls to about $90 \%$ in the output cross-section $\left(z=z_{\text {out }}\right)$ of the cavity. Such a degradation of the output mode purity is shown in Fig. 6 and should be taken into design consideration for the RF output system of the $0.3-\mathrm{THz}$ second-harmonic gyrotron. 


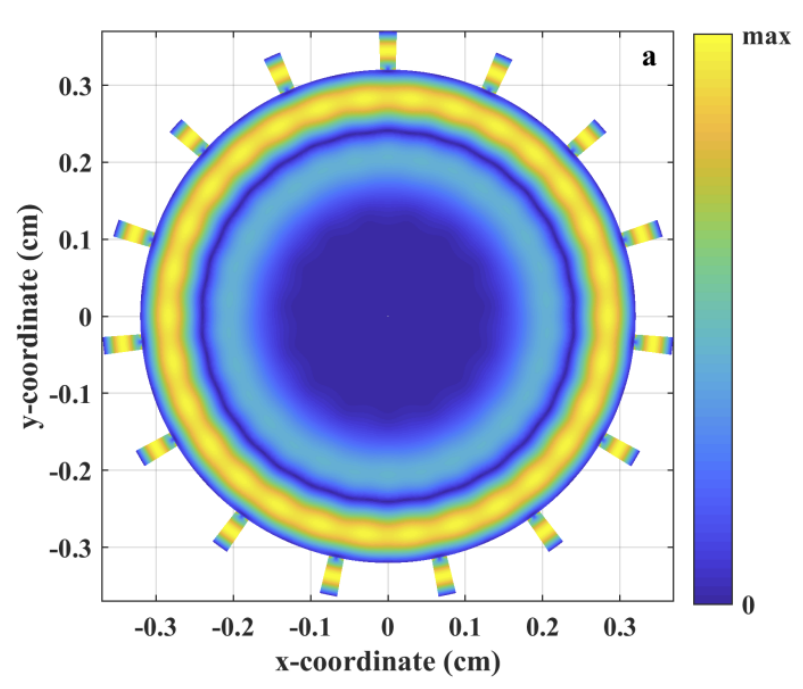

a

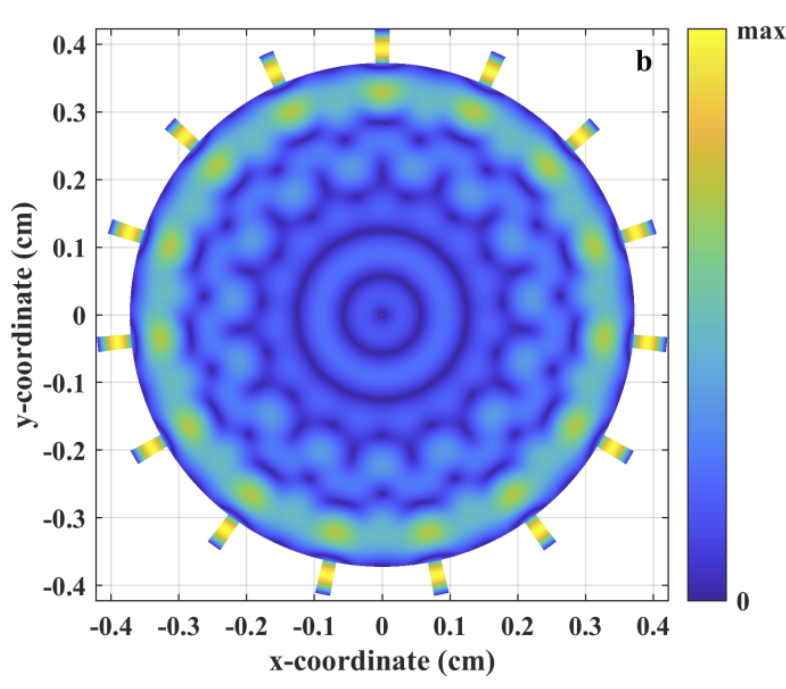

$\mathrm{b}$

Figure 6. The transverse structure of the azimuthal electric field $\left|E_{\varphi}\right|$ of the operating mode in (a) the main section and (b) output end of the corrugated cavity for the $0.3-\mathrm{THz}$ second-harmonic gyrotron

\section{CONCLUSIONS}

Longitudinal wedge-shaped corrugations are used to improve the selectivity properties of the cavity for secondharmonic gyrotron. As an example, a $0.3-\mathrm{THz}$ second-harmonic gyrotron designed for CTS diagnostics of fusion plasmas is considered. The gyrotron operates in the $\mathrm{TE}_{13,2}$ mode and its power-handling capability is limited by competition from the first-harmonic whispering-gallery modes. The full-wave method of coupled azimuthal harmonics is applied to investigate the eigenvalues, ohmic losses and beam-wave coupling coefficients of the second-harmonic operating and first-harmonic competing modes as functions of dimensions of a corrugated gyrotron cavity. For this cavity of the radius $R=0.32 \mathrm{~cm}$, the optimal depth $d=0.05 \mathrm{~cm}$, width $w=0.02 \mathrm{~cm}$ and number $N=15$ of corrugations are determined. Such optimized corrugations are shown to have a little effect on the operating secondharmonic mode, but cause rarefaction of the spectrum of the first-harmonic competing modes. The latter fact provides the possibility to extend the single-mode oscillation range of the operating mode to higher beam currents as demonstrated by the self-consistent theory of beam-wave interaction in the corrugated gyrotron cavity. For the $0.3-\mathrm{THz}$ second-harmonic gyrotron, this enables the operating beam current to be increased from 10 A to 15 A. Such increase in beam current is shown to imply the increase of the gyrotron output power from $100 \mathrm{~kW}$ to $180 \mathrm{~kW}$ and thus provides further improvement in performance of the $0.3-\mathrm{THz}$ second-harmonic gyrotron. In output wave radiated from the corrugated cavity of this gyrotron, the content of the operating mode is found to be about $90 \%$. This disadvantage calls for further investigation, but does not negate the advantages of using mode-converting wall corrugations in cavities of second-harmonic gyrotrons.

\section{ACKNOWLEDGEMENT}

The authors would like to thank Prof. John Jelonnek and Prof. Manfred Thumm from the Institute for Pulsed Power and Microwave Technology of the Karlsruhe Institute of Technology (Germany) for their interest in this work and helpful discussions. The work of Vitalii I. Shcherbinin was supported by the Georg Forster Research Fellowship for Experienced Researchers from the Alexander von Humboldt Foundation (Germany).

\section{ORCID IDs}

(D)Tetiana I. Tkachova, https://orcid.org/0000-0002-4605-3429; (DVitalii I. Shcherbinin, https://orcid.org/0000-0002-9879-208X (D)Viktor I. Tkachenko, https://orcid.org/0000-0002-1108-5842

\section{REFERENCES}

[1] R.J. Temkin, Int. J. Terahertz Sci. Technol. 7(1), 1-9 (2014), https://doi.org/10.11906/TST.001-009.2014.03.01.

[2] M.Y. Glyavin, T. Idehara, and S.P. Sabchevski, IEEE Trans. Terahertz Sci. Technol. 5(5), 788-797 (2015), https://doi.org/10.1109/TTHZ.2015.2442836.

[3] M. Blank, P. Borchard, S. Cauffman, K. Felch, M. Rosay, and L. Tometich, Int. J. Terahertz Sci. Technol. 7(4), 177-186 (2016), https://doi.org/10.11906/TST.177-186.2016.12.17.

[4] M. Thumm, J. Infrared Millim. Terahertz Waves 41(1), 1-140 (2020), https://doi.org/10.1007/s10762-019-00631-y.

[5] T. Notake, T. Saito, Y. Tatematsu, A. Fujii, S. Ogasawara, L. Agusu, I. Ogawa, T. Idehara, and V.N. Manuilov, Phys. Rev. Lett. 103(22), 225002 (2009), https://doi.org/10.1103/PhysRevLett.103.225002.

[6] T. Saito, N. Yamada, S. Ikeuti, S. Ogasawara, Y. Tatematsu, R. Ikeda, I. Ogawa, T. Idehara, V.N. Manuilov, T. Shimozuma, S. Kubo, M. Nishiura, K. Tanaka, and K. Kawahata, Phys. Plasmas 19(6), 063106 (2012), https://doi.org/10.1063/1.4729316. 
[7] T. Saito, S. Tanaka, R. Shinbayashi, Y. Tatematsu, Y. Yamaguchi, M. Fukunari, S. Kubo, T. Shimozuma, K. Tanaka, and M. Nishiura, Plasma Fusion Res. 14, 1406104 (2019), https://doi.org/10.1585/pfr.14.1406104.

[8] K.A. Avramides, C.T. Iatrou, and J.L. Vomvoridis, IEEE Trans. Plasma Sci. 32(3), 917-928 (2004), https://doi.org/10.1109/TPS.2004.828781.

[9] K.A. Avramides, J.L. Vomvoridis, and C.T. Iatrou, in: AIP Conference Proceedings 807, 264-270 (2006), https://doi.org/10.1063/1.2158787.

[10] V.I. Shcherbinin, V.I. Tkachenko, K.A. Avramidis, and J. Jelonnek, IEEE Trans. Electron Devices 66(12), 5313-5320 (2019), https://doi.org/10.1109/TED.2019.2944647.

[11] V.I. Shcherbinin, Y.K. Moskvitina, K.A. Avramidis, and J. Jelonnek, IEEE Trans. Electron Devices 67(7), 2933-2939 (2020), https://doi.org/10.1109/TED.2020.2996179.

[12] V.I. Shcherbinin, K.A. Avramidis, M. Thumm, and J. Jelonnek, J. Infrared Millim. Terahertz Waves 42(1), 93-105 (2021), https://doi.org/10.1007/s10762-020-00760-9.

[13] T.I. Tkachova, V.I. Shcherbinin, and V.I. Tkachenko, J. Infrared Millim. Terahertz Waves 40(10), 1021-1034 (2019), https://doi.org/10.1007/s10762-019-00623-y.

[14] T.I. Tkachova, V.I. Shcherbinin, V.I. Tkachenko, Z.C. Ioannidis, M. Thumm, and J. Jelonnek, J. Infrared Millim. Terahertz Waves 42(3), 260-274 (2021), https://doi.org/10.1007/s10762-021-00772-z.

[15] J.B. Davies, Proc. IEE-Part C 109(15), 162-171 (1962), https://doi.org/10.1049/pi-c.1962.0022.

[16] T. Scharten, J. Nellen, and F. van den Bogaart, Proc. IEE-Part H 128(3), 117-123 (1981), https://doi.org/10.1049/ip-h1.1981 .0019 .

[17] C.T. Iatrou, S. Kern, and A.B. Pavelyev, IEEE Trans. Microw. Theory Techn. 44(1), 56-64 (1996), https://doi.org/10.1109/22.481385.

[18] V.I. Shcherbinin, and V.I. Tkachenko, J. Infrared Millim. Terahertz Waves 38(7), 838-852 (2017), https://doi.org/10.1007/s10762-017-0386-x.

[19] V.I. Shcherbinin, B.A. Kochetov, A.V. Hlushchenko, and V.I. Tkachenko, IEEE Trans. Microw. Theory Techn. 67(2), 577-583 (2019), https://doi.org/10.1109/TMTT.2018.2882493.

[20] T.I. Tkachova, V.I. Shcherbinin, and V.I. Tkachenko, in: Proc. Int. Conf. Math. Methods Electromagn. Theory (MMET'2018) (Kyiv, Ukraine, 2018), pp. 238-241, https://doi.org/10.1109/MMET.2018.8460433.

[21] T.I. Tkachova, V.I. Shcherbinin, and V.I. Tkachenko, Problems Atomic Sci. Technol. 6(118), 67-70 (2018), http://dspace.nbuv.gov.ua/handle/123456789/148829.

[22] T.I. Tkachova, V.I. Shcherbinin, and V.I. Tkachenko, Problems Atomic Sci. Technol. 4(122), 31-34 (2019), https://vant.kipt.kharkov.ua/ARTICLE/VANT_2019_4/article_2019_4_31.pdf.

[23] V.I. Shcherbinin, A.V. Hlushchenko, A.V. Maksimenko, and V.I. Tkachenko, IEEE Trans. Electron Devices 64(9), 3898-3903 (2017), https://doi.org/10.1109/TED.2017.2730252.

\section{ГОФРИ З КОНВЕРСІЄЮ МОД ДЛЯ РЕЗОНАТОРІВ ГІРОТРОНІВ НА ДРУГІЙ ЦИКЛОТРОННІЙ ГАРМОНЦЦ ІЗ ПОЛІПШЕНИМИ РОБОЧИМИ ХАРАКТЕРИСТИКАМИ \\ T.I. Ткачова ${ }^{a}$, B.I. Щербінін ${ }^{a}$, B.I. Ткаченко ${ }^{a}$, \\ ${ }^{a}$ Національний науковий центр "Харківський фізико-технічний інститут", 61108 Харків, Украйна \\ ${ }^{b}$ Харківський національний університет ім. В.Н. Каразіна, 61022 Харків, Украӥна}

Досліджено новий метод поліпшення селекції мод в резонаторах суб-терагерцових гіротронів, які працюють на другій гармоніці циклотронної частоти. Як приклад розглянуто гіротрон на другій циклотронній гармоніці 3 частотою 0.3 ТГц. Гіротрон розробляється для застосування в системі діагностики термоядерної плазми на основі колективного Томсонівського розсіювання (CTS) та характеризується обмеженою потужністю внаслідок конкуренції робочої ТЕ 13,2 моди 3 модами на першій циклотронній гармоніці. Для пригамування конкуруючих мод на першій гармоніці в резонаторі гіротрона застосовані періодичні поздовжні гофри, що викликають зв'язок нормальних базисних мод, відомих як азимутальні гармоніки Блоха. Глибина цих гофрів була обрана близькою до половини та чверті довжини хвилі для робочої моди гіротрона та конкуруючих мод на першій циклотронній гармоніці, відповідно. За такої умови поздовжні гофри на стінці резонатора мають, як правило, лише неістотний вплив на робочу моду, але разом із тим можуть призводити до сильної конверсії конкуруючих мод у гармоніки Блоха високого порядку. Строгий метод зв'язаних азимутальних гармонік застосовано для дослідження впливу розмірів гофрованого резонатора на власні значення, омічні втрати та коефіцієнти зв'язку з пучком для робочої ТЕ 13,2 моди та найбільш небезпечних конкуруючих мод. За допомогою самоузгодженої теорії взаємодії пучка з робочою та конкуруючими модами визначені найбільш оптимальні параметри резонатора гіротрона із поздовжніми гофрами, які забезпечують найширший діапазон одномодової роботи 0.3-ТГц гіротрона на другій циклотронній гармоніці. Показано, що в даному діапазоні вихідна потужність гіротрона може бути збільшена зі 100 кВт до 180 кВт, як того потребує CTS діагностика плазми. Виявлено, що модова чистота на виході із резонатора 0.3-ТГц гіротрона на другій циклотронній гармоніці погіршується через гофрування резонатора, яке призводить до небажаного зв'язку робочої моди $\mathrm{TE}_{13,2}$ із сусідніми гармоніками Блоха у вихідний секції резонатора гіротрона.

КЛЮЧОВІ СЛОВА: гіротрон, циклотронна гармоніка, резонатор, гофри 3 конверсією мод, стартовий струм, вихідна потужність. 